\title{
A EXCLUSÃO DA MULHER DO CÂNONE LITERÁRIO INGLÊS: O CASO DE CHARLOTTE DACRE
}

Paula Pope Ramos

Resumo: Este artigo tem como objetivo, a partir da trajetória traçada por Virginia Woolf, em seu ensaio-novela, Um teto todo seu (1929), delinear as causas que residem na raiz do apagamento da autora gótica Charlotte Dacre do cânone literário inglês. Dacre, assim como diversas escritoras anteriores ao surgimento do romance no cenário da literatura inglesa no século XVIII, chega à contemporaneidade com um nome obscuro e pouco conhecido. Por trás desse esquecimento parece existir uma força gerada no cerne de uma sociedade patriarcal que ora enclausura a mulher em uma vida doméstica e privada e ora lhe interdita o saber, de modo que os textos que ela poderia produzir deveriam corresponder a essa realidade. Na contramão dessa expectativa, Charlotte Dacre afasta-se de uma escrita considerada feminina quando, em suas obras, dá vida e palco central a mulheres violentas e predadoras sexuais. Consequentemente, os seus textos foram duramente criticados e preteridos por uma crítica especializada de cunho sexista e moralista. A fim de traçar a importante contribuição da autora não somente para a poética gótica, mas também a maneira como alimentou o imaginário de autores por vir, este trabalho se insere na tentativa de lançar luz sobre a sua vida e obra. Assim, aborda, com fins introdutórios, os seus romances e alguns de seus versos, sobretudo aqueles alimentados por mulheres fatais e por inclinações sádicas. Por fim, pretende-se, a partir dessa incursão, redimir o silêncio crítico histórico sobre a autora, de modo a reinscrevê-la nos círculos literários atuais, bem como atualizar a discussão crítica ao redor de suas obras.

Palavras-chave: Charlotte Dacre. Poética gótica. Mulheres escritoras.

Abstract: This article aims, following Virginia Woolf's trajectory in her essay-novella, A Room of One's Own (1929), to delineate the causes that lie at the root of the erasure of the Gothic author Charlotte Dacre from the English literary canon. Dacre, as well as several women writers before the emergence of the novel on the scene of English literature in the 18th century, arrives at contemporary times with an obscure and barely-known name. At the source of such oblivion, there 
seems to be a force generated at the heart of a patriarchal society that at times encloses women in domestic and private life and, in other moments, interdicts their knowledge so that the texts that they could produce should correspond to such reality. Fleeing this expectation, Charlotte Dacre moves away from a style of writing considered feminine when, in her works, she gives life and center stage to women who are violent and sexual predators. Consequently, her texts were severely criticized and disregarded by a specialized criticism of a sexist and moralistic nature. To trace the author's important contribution not only to the Gothic Poetics, as well as how she has fuelled the imagination of authors to come, this paper is part of the attempt to shed light on her life and work. Thus, it approaches, with introductory purposes, her novels and some of her poems, especially those fed by fatal women and sadistic inclinations. Finally, it intends, based on this incursion, to redeem the historical-critical silence about the author, to reinscribe her in current literary circles, as well as to update the critical discussion around her works.

Keywords: Charlotte Dacre. Gothic Poetics. Women writers.

\section{INTRODUÇÃO}

A mulher escritora foi, durante longos anos, preterida e excluída do cânone literário. Entre os motivos para tal apagamento, Virginia Woolf, em seu ensaio-novela Um teto todo seu (1929), identifica a escassez de condições materiais para que ela pudesse então penetrar um âmbito há muito constituído como um local de saber tipicamente masculino. Daí a célebre frase da autora, "a mulher precisa de dinheiro e de um teto todo seu se pretende mesmo escrever ficção" (WOOLF, 2019 [1929], p. 9), que dá os contornos para o entendimento de um problema tão complexo: a questão ao 
redor da baixa produção literária das mulheres, em contexto inglês até o século XIX, como nota Woolf, está para além da genialidade da artista, pois o que se encontra no cerne desse debate são, na verdade, dilemas econômicos e culturais que ora lhe interditam o saber e ora lhe enclausuram em espaços domésticos. É então a partir dessa falta que a autora inicia, no escopo da literatura inglesa, uma busca por mães literárias de escritoras de outrora, suas contemporâneas ou, ainda, as por vir.

No percurso de sua empreitada Virginia Woolf utiliza nomes de escritoras como Margaret de Newcastle, Dorothy Osborne, Lady Winchilsea, Jane Austen e Emily Brontë a fim de ilustrar a sua argumentação. Contudo, Ihe escapa o fato de que também durante esse período é consolidada a poética gótica, extremamente popular entre as mulheres. Nesse tipo de ficção, o interesse feminino não se limitava à leitura, mas também se estendia para a escrita dessas obras, pois como nota Lyn Pykett, em seu capítulo, "Sensation and the fantastic in the Victorian Novel", para a antologia The Cambridge Companion to the Victorian Fiction (2001, p. 198), a ficção gótica era atrativa para as mulheres em virtude de suas recorrentes figurações assustadoras da experiência feminina, bem como toda a sua parafernália de castelos 
claustrofóbicos, vilões dominadores e o aprisionamento da mulher em locais domésticos, assim como refletia, em diferentes níveis, sobre a precariedade de suas vidas. E, desse modo, Woolf não considera autoras góticas como Clara Reeve, que na segunda metade dos anos setecentos contribuiu para a estruturação do gótico, ou, talvez ainda mais alarmantemente, Ann Radcliffe, escritora prolífica cujos números comerciais atingiram patamares excepcionais, até mesmo em comparação com os seus colegas de profissão.

É ainda em meio às mulheres góticas soterradas em um cânone preenchido por escritores como Horace Walpole, Matthew Gregory Lewis, Charles Maturin e James Hogg, para citar apenas alguns exemplos, que se encontra um nome bem-sucedido durante a sua vida, mas que raramente é discutido nos círculos literários atuais: Charlotte Dacre. Nos contextos em que seu nome é mencionado, muitos deles de maneira superficial, encontram-se breves aparições em antologias sobre o gótico, em linhas temporais ou em trabalhos de caráter documental. Ela figura com um pouco mais de frequência quando associada a Lewis, sobretudo quanto à discussão sobre a crítica e a recepção de The Monk (1796), tendo em vista certa afinidade literária entre as obras de Dacre e as do autor. Assim, observa-se que a 
questão acerca de seu desconhecimento é menos uma completa ignorância de seus escritos e mais um desinteresse ao redor de sua obra, ocasionado pelo apagamento de sua contribuição para a tradição literária inglesa, tendo Dacre inclusive alimentado o imaginário de grandes autores do século XIX, como os poetas românticos Lord Byron e Percy Shelley, bem como Emily Brontë.

Este artigo, portanto, insere-se na esteira da trajetória de Woolf em Um teto todo seu. No percurso das páginas seguintes pretende-se resgatar, com fins introdutórios, a vida e a obra de Charlotte Dacre, bem como delinear as possíveis raízes de seu apagamento, de modo a reinscrevê-la no cânone da literatura inglesa e na tradição da poética gótica. E, dessa forma, contribuir para a historiografia literária, sobretudo quanto aos estudos sobre o gótico produzido por mulheres que, como é o caso de Dacre, se afasta das expectativas impostas à escrita de autoria feminina.

\section{A VIDA DE CHARLOTTE DACRE E A SUA PRODUÇÃO LITERÁRIA}

Não há longos trabalhos bibliográficos e críticos dedicados à Charlotte Dacre e tampouco as suas obras são de fácil acesso, de maneira que a maior parte das informações que atualmente estão disponíveis sobre a autora encontram-se em introduções às edições de seus escritos, sobretudo de 
seu romance mais conhecido, Zofloya, or the Moor (1806). Isso constitui uma consequência de seu apagamento da historiografia literária e Dacre, assim como muitas outras escritoras que antecedem o século XIX, chega à atualidade com uma vida obscura e enigmática. Observase a dificuldade em estabelecer afirmações com exatidão sobre sua vida a partir da tentativa de decidir a sua data de nascimento. Essa confusão, no entanto, é também causada pela própria autora. Dacre, em prefácio ao público em sua coleção de poemas, Hours of Solitude (1805), afirma que "na idade de 23 anos, portanto, não tendo mais a juventude extrema para suplicar pela atenuação de seus erros [dos poemas], devo apenas recomendá-los à misericórdia"1 (DACRE, 1805, p. vii). É dessa forma que Paul Baines (2015), em seu verbete sobre a autora para o Oxford Dictionary of National Biography, identifica o seu nascimento em 1782. Há, todavia, um fato que contesta essa informação, pois um anúncio no obituário do The Times, publicado em 1825, comunica a morte de Dacre, aos 53 anos de idade, de modo que a sua data de nascimento seria então dez anos antes, entre 1771 e 1772. É levando em consideração esse dado que E.J. Clery, em capítulo dedicado a autora em seu livro

1 As traduções presentes neste trabalho são de minha autoria. No original, em inglês: "At the age of three-and-twenty, therefore, having no longer extreme youth top lead in extenuation of their errors, I must merely recommend them to mercy". 
Women's Gothic (2000, p. 100), argumenta que a declaração da escritora sobre a sua idade, bem como as diversas notas que ela acrescenta em seus poemas ao destacar versos que teriam sido escritos ainda em sua adolescência, são, na verdade, mais um autoelogio à sua genialidade precoce que, de fato, um dado factível e relevante para o leitor.

As suas origens familiares também são foscas, embora não tão discutíveis. Charlotte Dacre, nascida Charlotte King, é filha de Jonathan King (por sua vez, nascido Jacob Rey, 1753-1824) e de Sara que, de acordo com Baines (2015), é nascida Lara, ou, como afirma Adriana Craciun (1997, p. 36) em sua introdução à edição da Broadview Press de Zofloya, Deborah Lara. Seus pais divorciaramse em 1784, de modo que não havia impedimento para que seu pai se casasse com a condessa de Lanesbourogh, previamente sua amante. Quanto a este fato, a crítica aponta o seu impacto sobre a escrita de Dacre, sendo um de seus temas principais "mulheres abandonadas por parceiros infiéis, como parece ter sido o caso de sua mãe"2 (CRACIUN, 1997, p. 13). Charlotte é também irmã de Sophia $\mathrm{King}^{3}$, autora de romances como Waldorf (1798),

2 "women abandoned by unfaithful partners, as it appears her mother was".

3 Devido à pouca informação que se tem sobre Sophia King (posteriormente, Fortnum) e sendo ela a irmã mais nova de Dacre, estima-se que ela tenha nascido por volta do final do século XVIII, em 1782, e falecido após a publicação de seu último romance em 1805, embora não se tenha certeza de em que década. 
The Fatal Secret (1801) e Victor Allen (1805), entre outros títulos compostos por poemas.

A afirmação sobre a sua paternidade é sustentada com base em seu volume de poesias, Trifles of Helicon (1798), publicado com sua irmã e dedicado ao seu pai, que há pouco havia ido à falência. A sua relação com o seu progenitor é importante, pois é a partir dele que se costura a sua ligação com grandes autores e filósofos dos anos setecentos e oitocentos, como William Godwin, Lord Byron e Percy Shelley. Jonathan King, um judeu e influente banqueiro em Londres, foi também escritor e apoiador de causas radicais e a sua associação e de suas filhas aos nomes citados acima era, então, inevitável. Observa-se essa troca de influências mais profundamente com os dois poetas: Percy Shelley escreveu duas novelas góticas, Zastrozzi: a romance e St. Irvyne; or, The Rosicrucian, ambas publicadas em 1811, sob uma forte impressão de Zofloya, de modo que reproduz em suas páginas enredo, cenas e nomes quase integralmente iguais aos de sua antecessora. Esse vínculo é notado por Thomas Medwin, primo e biógrafo do poeta, que em seu livro, The Life of Percy Bysshe Shelley (1847), faz a seguinte declaração:

Os trabalhos de Anne Radclyffe [sic] o agradavam mais, particularmente The 
Italian, mas a escola de Rosa-Matilda, especialmente um romance estranho e selvagem, intitulado Zofloya, or the Moor [...], na qual sua majestade Satânica, como em Faust, desempenha o papel principal, arrebatou-o. Os dois romances que ele escreveu depois, intitulados Zastrozzi e [St. Irvyne] The Rosicrucian, foram modelados segundo essa produção medonha [...]. ${ }^{4}$ (MEDWIN, 1913 [1847], p. 25)

Assim, estabelecem-se os vínculos entre ambos os autores. A. M. D. Hughes, em artigo intitulado "Shelley's Zastrozzi and St. Irvyne" (1912), delineia a contribuição de Dacre para a produção literária de Shelley. Em Zofloya e Zastrozzi, por exemplo, além da clara similaridade entre os títulos, ambas as narrativas tomam emprestados os nomes de seus vilões, o Mouro Zofloya e Zastrozzi. Quanto ao enredo, as duas histórias desenrolam-se a partir da trajetória cruel e sádica de suas protagonistas, Victoria em Dacre e Matilda em Shelley, que, inundadas por um desejo sexual intenso e com a ajuda dos vilões, manipulam, perseguem e assassinam suas vítimas, homens e mulheres, em benefício próprio. Enquanto Victoria declara à Zofloya que “'Este coração não sabe encolher [...] e em seu

4 "Anne Radclyffe's works pleased him most, particularly The Italian, but the Rosa-Matilda school, especially a strange, wild romance, entitled Zofloya, or the Moor [...], where his Satanic Majesty, as in Faust, plays the chief part, enraptured him. The two novels he afterwards wrote, entitled Zastrozzi and The Rosicrucian, were modelled after this ghastly production [...]". 
propósito perseveraria, até a destruição!'”5 (DACRE, 2008 [1806], p. 152), Matilda, por seu turno, ecoa a voz de sua antecessora quando diz, "'Não, não - este coração não sabe temer - este seio não sabe encolher.'"'6 (SHELLEY, 2018 [1810], p. 45). E embora elas trilhem caminhos semelhantes, Shelley concede o destino de sua mulher fatal às mãos da divindade, pois no dia de seu julgamento, em decorrência dos crimes que cometeu ao longo de sua narrativa, Matilda se arrepende. Victoria, por outro lado, recusa a oferta de salvação de um anjo, pois entende que a postergação de seus prazeres, ou, nesse caso, a sua completa cessão, é um destino mais cruel que a eternidade no Inferno.

Acerca de sua troca com Lord Byron, Jerome J. McGann, em seu capítulo, "'My Brain is Feminine': Byron and the Poetry of Deception", no livro Byron: Augustan and Romantic (1990), traça a influência de Dacre sobre o poeta: desde a confusão da autoria do poema "The Mountain Violet", de Dacre em Hours of Solitude, até os constantes encontros e desencontros entre ambos. McGann (1990, p. 28) aponta, no poema "The First Kiss of Love" (1807) de Byron, reflexos do mesmo sentimentalismo encontrado em Dacre, como nos seus versos em "The Kiss", "The Sovereignty of Love" e

5 "'This heart knows not to shrink [...] and in its purpose would persevere, even to destruction!".

6 "No, no - this heart knows not to fear - this breast knows not to shrink". 
"To Him Who Says He Loves". Além de, mais explicitamente, o nome da coleção de poemas do poeta, Hours of Idleness (1807), cujo formato imita Hours of Solitude, publicado somente dois anos antes.

Entretanto, em pouco tempo Byron desvia o rumo de sua poesia e escreve English Bards and Scottish Reviewers (1809), no qual se refere à prosa de Dacre como "masquerade"7, bem como adiciona uma nota:

Essa adorável pequena Jessica, filha do notável J[udeu] King, parece ser uma seguidora da escola Della Crusca, e publicou dois volumes de absurdos muito respeitáveis em rima, [...]. Além de diversos romances no estilo da primeira edição de The Monk. ${ }^{8}$ (BYRON, 1809, p. 58)

Nesse livro, Byron marca o seu afastamento artístico de um estilo de poesia mais sentimental, como é possível observar em Fugitive Pieces (1806), por exemplo, em direção às sátiras e às histórias de viagens, bem como a uma poesia mais heroica. E, no cerne dessa ruptura e ridicularização de Dacre, McGann, afirma que "ele

7 Integralmente, o quarto mencionado:

Far be't from me unkindly to upbraid

The lovely ROSA's prose in masquerade,

Whose strains, the faithful echoes of her mind,

Leave wondering comprehension far behind. (737-40)

8 This lovely little Jessica, the daughter of the noted Jew K[ing], seems to be a follower of the Della Cruscan School, and has published two volumes of very respectable absurdities in rhyme, [...]; besides sundry novels in the style of the first edition of the Monk. 
simplesmente a ataca [Charlotte Dacre] por um tipo de escrita da qual ele mesmo foi afastado porque essa escrita havia ofendido certos leitores provinciais"9 (1990, p. 30), de modo que essa mudança de atitude parece refletir mais uma pressão sobre a sua produção literária que de fato uma ruptura espontânea.

Nessa nota de Byron é interessante observar a aproximação que o poeta faz entre Dacre e a escola Della Crusca $^{10}$, um grupo de poetas conhecido no século XVIII por sua poesia repleta de sentimentos exaltados e excessivos, bem como uma dicção ornamentada. Além disso, era comum entre os seus integrantes o uso de "Matilda" como um pseudônimo. E foi assim, como Rosa Matilda, que Charlotte Dacre alçou sua fama no século XIX. Para essa escolha, os críticos da obra de Dacre apontam dois motivos: pode tratar-se de, como já mencionado, uma afinidade com a escola literária Della Crusca; ou, por outro lado, ser uma referência à femme fatale de Lewis em The Monk, Rosario e, posteriormente, Matilda, o que denota, já de partida, as suas intenções literárias.

\footnotetext{
9 "he simply attacks her for a kind of writing which he himself had been driven from because the writing had offended certain provincial readers".

10 Nome derivado da Academia dela Crusca, fundada em 1582, cujo objetivo era proteger a pureza da língua italiana. Na Inglaterra, ganhou força especialmente por meio dos trabalhos de Robert Merry, sendo os mais conhecidos Arno Miscellany (1784) e The Florence Miscellany (1785).
} 
Como "Rosa Matilda" ela publicou sua poesia nos jornais londrinos Morning Post e no Morning Herald por um período estimado entre 1802 e 1815. Além de sua coleção de poemas, Trifles of Helicon (1789), publicado por Charlotte e Sophia King, Rosa Matilda escreveu Hours of Solitude (1805), no qual alguns poemas de sua primeira publicação reaparecem - 0 que, por sua vez, tornou possível conectar Charlotte King à Rosa Matilda e, posteriormente, à Dacre. Seus versos são, como observou Byron, influenciados pelo formato dos Della Cruscan e lidam quase exclusivamente com as consequências da paixão, cobrindo um espectro que abrange desde a melancolia, a angústia e pesadelos; bem como têm também descrições de insanidade e baladas de horror, muitas delas com a presença de um amante demoníaco.

Ainda sob o seu pseudônimo a autora publicou o seu primeiro romance, The Confessions of the Nun of St. Omer (1805), o qual, dedicado a Lewis, ela alega ter escrito aos dezoito anos de idade. Descrito por Baines como um "conto gótico de repressão sexual e mau comportamento"11 (2015, s.p.), a narrativa tem como protagonista Cazire que, do convento onde se isola, reconta as aventuras apaixonadas e destrutivas de sua juventude. Esse romance mostra um lado da autora mais politicamente engajado, ecoando a Revolução

11 "Gothic tale of sexual repression and misbehaviour". 
Francesa (1789-1799), mas que, contudo, ainda lida com assuntos importantes no que diz respeito a ser mulher, como a paixão e os perigos da sedução.

Um ano depois, a autora se despede de Rosa Matilda e passa a assinar os seus trabalhos como Charlotte Dacre, também outro pseudônimo e que Baines (2015) classifica como uma tentativa de soar mais aristocrática; mas é, ainda assim, o nome adotado pela crítica contemporânea. Seu segundo romance, Zofloya, or the Moor: a romance of the fifteenth-century (1806), assim como The Monk, se insere em uma tradição de uma literatura erótica gótica. Segue a trajetória de Victoria di Loredani que, auxiliada pelo Mouro Zofloya, busca a realização imediata de todos os seus prazeres sexuais e, para tanto, perpassa o assassinato de quatro indivíduos, entre eles o seu marido, o seu cunhado e a sua jovem noiva. O desfecho da anti-heroína Victoria, assim como acontece em muitos romances góticos, não é exitoso e ela morre atirada de um abismo por Zofloya que então se revela como Satã. Esse romance é a sua obra de maior sucesso, tendo vendido rapidamente 754 das 1.000 primeiras cópias impressas (CRACIUN, 1997, p. 11), bem como também foi objeto de traduções para o francês e para o alemão, como aponta Kin Ian Michasiw (2008, p. xiii), 
em sua introdução à edição da Oxford University Press do romance. Zofloya recebeu ainda uma imitação em formato de chapbook, intitulada The Daemon of Venice (1810), cuja autoria é desconhecida ${ }^{12}$.

Dacre publicou ainda outros dois romances, The Libertine (1807), no qual, mais uma vez, explora abertamente a sexualidade feminina, o que levou a uma resenha crítica do seu trabalho na seção "Novels and Romances" da Monthly Magazine (1807, p. 657) à declaração de que os apreciadores de tal obra deveriam ter "seus apetites mentais depravados, e seus entendimentos distorcidos em um grau incomum"13. Em meio às aventuras eróticas e aos relatos de irresponsabilidade parental, a narrativa gira em torno dos infortúnios que se sucedem na vida de Gabrielle, abandonada por seu amado, Angelo, em troca de promessas de amor de outra mulher. Em uma sequência de tramas vingativas, na qual em uma delas Gabrielle se veste de homem, a história termina, assim como Zofloya, sem um fim moral ao qual o leitor poderia se agarrar, uma vez que todas as personagens, inocentes e pecadoras, são destruídas.

12 Adriana Craciun (1997), em uma nota ao seu texto, discorre sobre a possibilidade, embora pouco provável, de Dacre ser também a autora desse livro, tendo em vista que seu nome, "Miss Dacre", era associado à publicação de outro chapbook, The School for Friends, publicado pela mesma editora, a de Thomas Tegg.

13 "their mental appetites depraved, and their understandings warped in no common degree". 
Já em The Passions (1811), seu último romance, Dacre mais uma vez dá palco central a uma mulher fatal. Craciun, em Fatal Women of Romanticism (2003, p. 130), identifica na história uma versão estendida de uma das narrativas de M. D. T. Bienville em Nymphomania, or A Dissertation Concerning the Furor Uterinus (1775), em combinação com Julie, ou La Nouvelle Héloïse (1761), de Jean-Jacques Rousseau. Nesse romance, Dacre mantém "Julia" como o nome de uma das protagonistas, mas é a anti-heroína Appollonia, com "suas aspirações satânicas e solilóquios que rivalizam com os de um herói byroniano"14 (CRACIUN, 2003, p. 130), que desencadeia os acontecimentos da narrativa: ela, a condessa Zulmer, planeja uma vingança contra o conde Weimar após ele tê-la rejeitado por sua nova noiva, Julia. E para tanto, dedica-se a seduzi-la e corrompê-la em cenas que sugerem lesbianismo e ninfomania, de modo a degenerá-la em uma mulher adúltera. Assim como nos dois romances que antecedem Passions, Appollonia, potencializada por suas paixões violentas, é instrumental na destruição de todas as personagens femininas, inclusive ela mesma.

Após uma longa pausa, Charlotte Dacre publicou um poema, "George, the Fourth" (1822), em homenagem ao então rei da Grã-Bretanha. Quanto à sua vida, sabe-se que

14 "her Satanic aspirations and soliloquies that rival those of a Byronic hero". 
em algum momento ela engatou um romance adúltero com Nycholas Byrne, editor do Morning Post, e que tiveram três filhos: William, Charles e Mary, nascidos, respectivamente, em 1806, 1807 e 1809. Casaram-se somente em julho de 1815, presumivelmente após a morte da esposa de Byrne. Um obituário do The Times de 9 de novembro de 1825, citado anteriormente, informa que a senhora Byrne, Charlotte Dacre, morrera na segunda-feira anterior em Lancaster, após uma longa e dolorosa doença, a qual "sua pureza de coração e sublime grandeza de alma permitiu-lhe suportar com paciência e coragem"15 (1825, s.p.). O seu corpo encontrase sepultado em Londres, no cemitério de St. Mary's, em Paddington.

\section{EXCESSIVAMENTE SUBVERSIVA: O APAGAMENTO DE DACRE DO CÂNONE LITERÁRIO INGLÊS}

Charlotte Dacre configura mais um caso de uma escritora apagada de um cânone literário majoritariamente masculino como é o inglês, sobretudo até o século XIX. Escrever não era uma empreitada simples para uma mulher inglesa de séculos atrás, porém, como muitos estudos se empenham em demonstrar, a produção artística feminina não era inexistente. Entre esses trabalhos destaca-se com

15 "her purity of heart and sublime greatness of soul enabled her patiently and proudly to endure". 
mais frequência o de Virginia Woolf que, em Um teto todo seu, resgata a história de mulheres escritoras em uma tentativa de reinscrevê-las na tradição literária. É em seu ensaio-novela que ela aponta para o fato de que a mulher, talvez “o animal mais discutido do planeta" (WOOLF, 2019 [1929], p. 30), é objeto de diversos escritos, desde os que se dedicam à discussão de sua suposta inferioridade biológica, social e moral, à elaboração de cartilhas de seus deveres como uma proper lady, até mesmo aqueles que a tomam como musa inspiradora. Todavia, um elemento curioso é que esses textos, em sua grande maioria, são escritos por homens sem qualquer qualificação, com exceção do fato de serem homens.

Assim, proibiram à mulher o seu caminhar pelo gramado e impuseram-lhe caminhos já pavimentados, préestabelecidos e, em consequência, limitados. Além de sua presumida condição de inferioridade, a mulher burguesa, aquela que dispunha de tempo livre para dedicar-se à leitura, foi também enclausurada no espaço doméstico e privada de uma educação formal abrangente. Dessa forma, sempre dependente e subordinada a um homem, o seu pai ou marido, Ihe faltava tanto dinheiro quanto um espaço para o exercício de sua criatividade. A vida trágica que Woolf 
(2019 [1929], p. 47-9) cria para a irmã fictícia de William Shakespeare ilustra, de maneira didática, o destino da mulher do período elisabetano (1558-1603) que, com muito esforço, ousava ultrapassar esses obstáculos. Judith, em sua ingenuidade, acredita dispor das mesmas oportunidades que o irmão, e a sua busca por realização artística culmina apenas em humilhação, rejeição e suicídio.

Se a mulher elisabetana não era incentivada à produção artística, tampouco era a georgiana (1714-1830), mas é nesse período que tal panorama começa a ser alterado. É no século XVII com escritoras como Aphra Behn e Delavivière Manley e, no seguinte, com Eliza Haywood, Clara Reeve e Ann Radcliffe, por necessidades financeiras ou por simples prazer, que a mulher se insere, embora timidamente, no mercado literário. Essas mulheres mostraram que ganhar dinheiro escrevendo era uma possibilidade para o seu sexo, mesmo que isso significasse colocar em risco a sua reputação.

É a partir desse esforço que se torna possível, nos anos setecentos, a inserção definitiva da mulher na produção literária, sobretudo com a ascensão do romance, o modo narrativo favorito da época. De acordo com as lições de Sandra Guardini Vasconcelos (2002, p. 29), foi a origem bastarda do novo gênero literário, maleável e desprovido 
de regras fixas, que facilitou a introdução da mulher, com baixos níveis de instrução formal e sem todo o arsenal de leitura clássica do qual dispunha os homens, nessa nova profissão. Assim, o romance, livre de uma tradição cristalizada sobre a qual se estruturar, foi o principal condutor da voz das mulheres setecentistas e oitocentistas. Ademais, nascido no seio da burguesia, ele era tanto produto quanto produtor de sua ideologia, de modo que transmitia didaticamente os seus valores e a sua moral. Portanto, percebe-se que os mesmos princípios e códigos morais impostos às mulheres deveriam prevalecer em seus textos, ao ponto de o gênero (gender) também atuar em repressão ao novo gênero (genre).

Nesse contexto, um que exigia da literatura certo realismo e correspondência com a vida em sociedade, surge o romance gótico. A poética gótica é descrita por Fred Botting, em Gothic (2005, p. 1), como uma escrita de excessos obcecada por transgressões de limites. Em seu período de maior profusão, na década final do século XVIII, o seu sucesso comercial atingiu patamares significativos, pois como nota Robert Miles, em seu artigo "The 1790s: the effulgence of Gothic", para o livro The Cambridge Companion to Gothic Fiction (2002, p. 42), os romances góticos alcançaram um 
pico de $38 \%$ de circulação no mercado literário em 1795 . E a crítica, por sua vez, respondeu à altura do desafio, como se observa na seguinte passagem do artigo The Terrorist Novel Writing (1798), de autoria anônima:

Que instrução deve ser obtida a partir das ideias distorcidas de lunáticos, não consigo conceber. [...] Os deveres da vida estão tão alterados ao ponto de todas as instruções necessárias a um jovem é aprender a caminhar à noite pelas ameias de um castelo antigo, deslizar as mãos ou os pés por uma passagem estreita, e encontrar o diabo no final? ${ }^{16}$ (THE TERRORIST NOVEL WRITING, 2000 [1798], p. 184)

De acordo com o trecho acima, no qual a parafernália gótica é criticada em razão dos ensinamentos morais que a literatura deveria, em sua responsabilidade educativa, inspirar nos indivíduos, compreende-se a resposta da crítica especializada a um romance cuja protagonista é descrita como "de uma natureza implacável, vingativa e cruel, empenhada em obter domínio em tudo que se engajasse"17 (DACRE, 2008 [1806], p. 4). É segundo esses termos que Victoria di Loredani é caracterizada, ainda

16 "But what instruction is to be reaped from the distorted ideas of lunatics, I am at a loss to conceive. [...] Are the duties of life so changed, that all the instructions necessary for a young person is to learn to walk at night upon the battlements of an old castle, to creep hands and feet along a narrow passage, and meet the devil at the end of it?".

17 "of an implacable, revengeful, and cruel nature, and bent upon gaining ascendancy in whatever she engaged". 
aos quinze anos de idade, nas páginas inicias de Zofloya. Dacre apresenta ao leitor uma mulher naturalmente cruel, sádica e violenta que apesar de ser insensível aos afetos, era capaz de "infligir dor sem remorso, e podia vingar-se amargamente da menor tentativa de infligi-la nela"18 (DACRE, 2008 [1806], p. 78). Em sua associação com Satã, Victoria planeja e executa assassinatos por envenenamento e até mesmo um estupro. Tendo em vista os seus padrões agressivos de comportamento, como seria possível reconciliar tal personagem feminina, a protagonista do romance, com as figuras típicas das heroínas góticas que, tal como Emily St. Aubert, em The Mysteries of Udolpho (RADCLIFFE, 1794), desmaia quando se depara com perigos potencialmente sobrenaturais?

Essa transgressão aos padrões de feminilidade exigidos da mulher burguesa inglesa parece ser consciente para a autora, pois em Zofloya ela oferece o contraponto à Victoria. Lilla, a noiva de seu cunhado, Henriquez, em uma aproximação com a metáfora que Virginia Woolf cria em "Profissões para mulheres" (1942), é a representação do Anjo do Lar: a imagem idealizada pela burguesia de benevolência e fragilidade supostamente inerentes à mulher. É tendo em

18 "inflict pain without remorse, and she could bitterly revenge the slightest attempt to inflict it on herself". 
mente esse modelo fictício que Lilla é descrita como "pura, inocente, livre até mesmo da menor mancha de qualquer pensamento corrupto"19 (DACRE, 2008 [1806], p. 133), ao passo em que sobre Victoria, apenas alguns parágrafos antes, a narradora afirma que "orgulho, teimosia, a gratificação de si, desprezo e ignorância das propriedades mais nobres da mente, com uma forte mancha de paixões mais sombrias, vingança, ódio e crueldade, compunham a soma de seu caráter juvenil"20 (DACRE, 2008 [1806], p. 132-133). A partir dessa comparação, é muito interessante observar o fato de Dacre, no romance, incumbir à Victoria o final trágico e violento de Lilla, pois em uma cena brutal e sangrenta, a jovem é esfaqueada à exaustão pela protagonista e depois atirada de um precipício, de modo que parece indicar uma revolta do instintivo/ID (Victoria) contra o culturalmente construído (Lilla).

Quando Virginia Woolf diz sobre a escritora que "era preciso ser uma espécie de incendiária" (2019 [1929], p. 72) a fim de não se conformar aos valores externos, isto é, masculinos, e ceder às advertências perpétuas de um pudor moralista, é exatamente esse o papel de Charlotte

19 "Pure, innocent, free even from the smallest taint of a corrupt thought".

20 "pride, stubbornness, the gratification of self, contempt and ignorance of the nobler properties of the mind, with a strong tincture of darker passions, revenge, hate, and cruelty, made up the sum of her early character". 
Dacre e de sua produção literária, da prosa à poesia. É em decorrência da composição de suas personagens, como visto acima, bem como a sua trajetória, que a crítica desferiu golpes cruéis às suas obras. Sobre Zofloya, o Monthly Literary Recrations observa que "raramente surgiu um romance tão vazio de mérito, tão destituído de sensibilidade, exibindo uma depravação tão repugnante"21 (1806, p. 80). A autora, com seus romances povoados por mulheres agressivas e predadoras sexuais, bem como com seus versos transbordando de paixões violentas, foi, então, preterida e obscurecida em virtude do teor de suas palavras.

$\mathrm{Na}$ sua coleção de poemas, Hours of Solitude, por exemplo, há uma recorrente conexão entre prazer e dor, algo que também reverbera em Zofloya. Se no romance Victoria, ao sequestrar Lilla a fim de desobstruir o seu caminho até Henriquez, declara que "certamente há um prazer [...] em infligir tormento prolongado"22 (DACRE, 2008 [1806], p. 206), no poema "To Him Who He Says He Loves", o eu-lírico investiga os limites do amor e em meio a uma série de perguntas, direciona a seguinte ao seu leitor: "Or do you faint with sweet excess / Of pleasure rising into pain / When hoping you may e'er possess / The object you

21 "there has seldom appeared a romance so void of merit, so destitute of delicacy, displaying such distinguishing depravity of morals".

22 "there is certainly a pleasure [...] in the infliction of prolonged torment". 
aspire to gain?" (1805, p. 27). Outro poema nessa coleção, "The Mistress to the Spirit of Her Lover", chega ao leitor em duas versões: uma em prosa ao estilo de Ossean e outra versificada. Ao longo dos versos, o eu-lírico, a Mistress, em completa agonia lamenta a morte de seu amante. E assim como Heathcliff, em Wuthering Heights (1847), de Emily Brontë, deseja ser assombrado pelo fantasma de Cathy em um evento que, conforme narra Nelly, "parecia transmitirIhe, a um só tempo, prazer e dor em grau extremo" (BRONTË, 2012 [1847], p. 266), a Mistress clama pela companhia de seu amante ${ }^{23}$ : “Ne'er leave me, bright shadow, wherever I rove / For dead is my soul to the accents of mirth" (1805, p. 34). Essa investigação sobre os limites do prazer que beiram na dor fez com que Dacre, assim como Lewis se vira forçado a editar a sua primeira edição de The Monk, caísse em uma espécie de purgatório moral, de modo que toda a sua produção literária sofria ataques, independente de suas virtudes. No caso da autora, no entanto, faltava-lhe um cargo no Parlamento britânico ou o fato de ser homem para desculpar as suas escolhas.

Ainda em seu incêndio à crítica literária, Dacre utiliza, em seus romances, palavras de léxico médico, como enhorred e

23 Para uma discussão mais ampla sobre a relação entre a poesia de Dacre e Wuthering Heights, ver Craciun (2003). 
furor, sendo esta uma referência ao "furor uterinus" do qual fala Bienville (1775) quando discorre sobre a ninfomania; em Zofloya, Victoria é dominada pelo "furor de paixões conflitantes"24 (DACRE, 2008 [1806], p. 134) quando vê Henriquez dedicando o seu afeto à Lilla. Em resposta, uma resenha crítica da Annual Review, declara que "Há uma voluptuosidade e alusão na linguagem [...] que deveríamos ter esperado que a delicadeza da pena feminina teria se recusado a traçar", e cujo teor "a delicadeza não nos permitirá explicar"25 (1806, p. 542 apud CRACIUN, 1997, p. 262-263). Percebe-se, então, que o material crítico produzido na época sobre a obra de Dacre era majoritariamente de cunho sexista, sobretudo por Zofloya ser um romance cujos objetos principais são o erotismo e a violência perpetrados por uma mulher. E assim, a crítica encerra com um conselho para a autora:

Em resumo, nunca lemos uma performance mais abominável e indecente [...]; e recomendaríamos a Rosa Matilda a continuar o caminhar humilde de versificar para os jornais, e deixar a profissão de escrever romances para as mulheres que possuem mais sensibilidade mental, [...] e pureza

\footnotetext{
24 "furor of conflicting passions".

25 "There is a voluptuousness of language and allusion [...] which we should have hoped, that the delicacy of the female pen would have refused to trace", "the delicacy will not permit us to explain".
} 
de sentimentos que ela [...]. ${ }^{26}$ (MONTHLY LITERARY RECREATIONS, 1806, p. 80)

Quanto aos seus romances, Craciun (2003, p. 130), argumenta que Dacre, em Confessions e The Libertine, explora em detalhes os perigos da paixão sexual em excesso, mas que em Zofloya e The Passions, por meio da figuração da femme fatale, a autora eleva essa discussão a níveis mais altos de franqueza e de significação cultural. Em Passions, Appollonia Zulmer é a protagonista e, tal qual Victoria, em razão de sua sexualidade e violência, desafia a fixidez de identidades pré-estabelecidas para a mulher, como se observa na descrição a seguir:

A condessa Zulmer... não se esforça em furtar suavemente o coração, mas ataca-o de assalto [...] destemida, indiferente a preconceitos, um espírito ardente e de intelecto ousado, ela discute opiniões, combate erros, expõe sistemas, detecta mentiras [...] Seus olhos ferozes e penetrantes parecem fitar o coração, com um olhar tão rápido, tão perfurante, que os outros olhos não conseguem encará-los e são abatidos, como com um sentimento de culpa. Altiva e excêntrica em seus voos, ela deixa o seu sexo prodigioso para trás. ${ }^{27}$

26 In short, we never read a more odious and indecent performance [...]; and would advise Rosa Matilda to keep to the humble walk of versifying for the newspapers, and to leave the profession of romance writing to females who possess more delicacy of mind, [...] and purity of sentiments, than she [...].

27 The Countess Zulmer... does not endeavour gently to steal into the heart, but attacks it by storm [...] fearless, regardless of prejudice, an ardent spirit and daring intellect, 
(DACRE, 1974 [1811], p. 27-28 apud CRACIUN, 2003, p. 137-138)

Desse modo, Appollonia, uma espécie de Medusa, se mostra como outra figura -satânica na produção literária de Dacre capaz de desafiar os limites da sexualidade feminina. Em sua sedução de Julia, descrita no início do romance como uma mulher perfeita, de uma "simplicidade casta, encantos acanhados - timidez, modéstia, prudência; [...] [com] um coração formado para o amor." ${ }^{28}$ (DACRE, 1974 [1811], p. 31 apud CRACIUN, 2003, p. 139), a condessa torna-se responsável por degenerá-la em uma mulher adúltera que, em sua queda, abandona a família, considera a possibilidade de assassinato e perde toda a estabilidade de sua vida. E assim como em Zofloya, Dacre isola dois modelos contemporâneos de subjetividade feminina, os dois extremos de mulheres na ficção de acordo com Woolf (2019 [1929], p. 80), “a bondade celestial" e a "depravação demoníaca", e os confronta. Em sua análise dos limites da psique e do corpo feminino, a autora os escreve em sua mais alta vulnerabilidade, pois o leitor os vê desfazendose de Lilla/Julia em Victoria/Appollinia, reiterando, segundo

she discusses opinions, combats errors, exposes systems, detects folly [...] Her fierce and penetrating eyes seem to look into the heart, with a glance so quick, so piercing, that other eyes are unable to meet them, and are cast down, as with a feeling of conscious guilt. Soaring, and eccentric in her flights, she leaves her wondering sex far behind. 
Craciun (2003, p. 116), "a compreensão da época de que corpos não são imutáveis ou naturalmente fixos" 29 .

Tendo em vista as personagens que compõem a obra de Dacre, pode-se compreender os motivos que residem em seu apagamento. E mesmo ao ser acusada por uma crítica sexista de escrever histórias imorais e indecentes, sobretudo por ser uma mulher, os seus escritos não cessam de refletir e de causar reflexões, mesmo dois séculos após a sua publicação, sobre os padrões de feminilidade e as políticas que regem o corpo da mulher. Diferente de algumas de suas companheiras de profissão, em seus trabalhos, como nota Douglas $\mathrm{H}$. Thomson, em um breve capítulo bibliográfico sobre a autora em Gothic Writers, "não temos o vilão-herói comum, mas mulheres, obstinadas e com mentes, saqueando esses tipos de gêneros"30 (2002, p. 100). Com as suas femmes fatales, Dacre põe à prova padrões de gênero e, como consequência de seu ataque, é deslocada da produção literária feminina.

A transgressão de Dacre a uma tradição de escrita feminina, até mesmo dentro do gótico, resulta em sua associação ao gótico masculino e à tradição de horror. Convencionalmente, o gótico é dividido em duas escolas, uma de terror e outra de horror, associadas aos nomes de Ann Radcliffe e Matthew 29 "the era's realization that bodies are not immutable or naturally fixed".

30 "we have not the usual villain-hero but women, strong-willed and with minds, ransacking these gender types". 
Lewis, respectivamente. Em linhas gerais, o terror, conforme aponta Jerrold E. Hogle, em sua introdução ao livro The Cambridge Companion to Gothic Fiction, "sustenta as personagens e os leitores em um suspense ansioso quanto ameaças à vida, segurança e sanidade, mantidas, em grande parte, fora de vista ou como sugestões de um passado oculto", ao passo em que o horror "confronta a dissolução física ou psicológica, explicitamente estilhaçando as normas estabelecidas (incluindo a repressão) da vida cotidiana"31 (2002, p. 2-3). É preciso, no entanto, observar que a associação do gótico feminino ao terror, caracterizado como mais discreto e contido, enquanto o reino do horror, com um apetite pelo grotesco, é designado ao gótico masculino, somente contribui para o aprisionamento da produção literária das mulheres a padrões de feminilidade correntes em sociedade. Ademais, a disputa entre um gótico masculino e outro feminino leva a uma hierarquização na qual o homem, invariavelmente, ocupará um lugar acima da mulher.

Desse modo, Dacre, com sua produção considerada nãofeminina e tampouco masculina, é, conforme argumenta Michasiw, "precisamente o tipo de escritora que o cânone,

31 "holds the characters and readers mostly in anxious suspense about the threats to life, safety, and sanity kept largely out of sight or in shadows or suggestions from a hidden past", "confronts the physical or psychological dissolution, explicitly shattering the assumed norms (including repression) of everyday life". 
tanto o estabelecido quanto o revisionista, está destinado a excluir"32 (2008, p. xiv). Ao desafiar os limites de uma literatura dita feminina, cujas linhas deveriam manterse dentro dos limites da probabilidade e, mesmo que eventualmente vertessem pelos caminhos sobrenaturais, deveriam manter fins educativos, Charlotte Dacre foi apagada e isolada do cânone literário inglês por um corpo crítico, por sua vez, composto majoritariamente por homens. Assim, a sua escrita, impossibilitada de ser masculina tendo em vista que o seu local de enunciação é outro, é não feminina quando comparada a de suas escritoras contemporâneas. Escrevendo a partir da margem, talvez tenha alcançado o que Woolf (2019 [1929], p. 93) defenderia um século mais tarde, uma escrita andrógina, que rejeita a dicotomia essencialista entre masculino e feminino, "masculino-femininamente" e "feminino-masculinamente".

\section{CONSIDERAÇÕES FINAIS}

O questionamento de Virginia Woolf (2019 [1929], p. 38) sobre o que acontece quando a mulher deixa de refletir, em tamanho dobrado, a imagem do homem, é respondido anacronicamente pelo apagamento literário de Charlotte Dacre: em uma sociedade heteropatriarcal na qual o local

32 "precisely the sort of writer whom canons, both established and revisionist, are designed to exclude". 
de saber é, por direito, do homem, a partir do momento em que a mulher transgride os limites que Ihe foram impostos, quando ela cessa de operar como espelho, conta a sua verdade e busca viver a sua existência, ela é aniquilada, silenciada, soterrada e esquecida. Quando Thomson (2002, p. 100) refere-se à obra de Dacre como uma das mais difíceis de encontrar na ficção inglesa, isso constitui um reflexo da violência cometida contra a mulher artista de séculos atrás que, por sua vez, reverbera até os dias atuais. Por isso é urgente a (re)descoberta de mulheres escritoras desviantes, excessivamente subversivas, pois as suas vozes, como em uma ligação direta com a contemporaneidade, dão corpo e sustentação às demandas da mulher do século XXI.

A partir da necessidade de traçar uma história para a mulher na literatura, neste caso, a de uma autora gótica, este artigo dedicou-se a resgatar elementos da vida de Charlotte Dacre, bem como de sua produção literária a fim de redimir o silêncio crítico sobre a autora e, nessa clave, conferir ao cânone literário mais pluralidade. Dacre, escritora inovadora, é tanto uma herdeira das mulheres que a antecederam quanto uma geradora para as que a seguiram. A sua exclusão do cânone do gótico inglês acontece em decorrência de uma compreensão sexista de que as mulheres, consideradas inferiores, deveriam dedicar-se a certo tipo de escrita 
mais casta e edificante moralmente. Elas, contudo, sempre constituíram resistência. Daí a importância de a mulher gozar de dinheiro e de um espaço privado a fim de que ela possa escrever, pois isso representa, de certo modo, a liberdade para encontrar a sua voz.

\section{REFERÊNCIAS}

BAINES, Paul. Byrne [née King]. Charlotte [pseud. Charlotte Dacre] (1782?-1825), escritora. Oxford Dictionary of National Biography, 2015. Available at: https://www.oxforddnb.com/view/10.1093/ ref:odnb/9780198614128.001.0001/odnb-9780198614128-e-63519. Accessed on: 21 $1^{\text {st }}$ Feb. 2021.

BOTTING, Fred. Introduction. In: BOTTING, Fred. Gothic. Londres: Taylor \& Francis e-Library, p. 1-13, 2005.

BRONTË, Emily. O Morro dos Ventos Uivantes. Tradução de Guilherme da Silva Braga. Porto Alegre: L\&PM, 2012.

BYRON, Lord. English Bards and Scottish Reviewers. 2. ed. Londres: Deans \& Co., 1809.

CLERY, E. J. Joanne Baillie and Charlotte Dacre. In: CLREY, E. J. Women's Gothic. Wiltshire: Bakersville Press, p. 99-116, 2000.

CRACIUN, Adriana. Introduction. In: DACRE, Charlotte. Zofloya, or the Moor. Ontario: Broadview Press, p. 10-33, 1997.

CRACIUN, Adriana. Fatal Women of Romanticism. Nova York: Cambridge University Press, 2003.

DACRE, Charlotte (1806). Zofloya, or the Moor. Nova York: Oxford University Press, 2008.

DACRE, Charlotte (1805). Hours of Solitude. Online Archive of California. Available at: https://oac.cdlib.org/view?docld=kt0v19p2vz;NAAN $=13030 \&$ doc.view $=$ frames\&chunk.id=d0e1244\&toc.depth=1\&toc. $i d=d 0 e 187 \&$ brand=oac4. Accessed on: $28^{\text {th }}$ Feb. 2021. 
HOGLE, Jerrold E. Introduction. In: HOGLE, Jerrold E. (Org.). The Cambridge Companion to Gothic Fiction. Cambridge: Cambridge University Press, p. 1-20, 2002.

HUGHES, A. M. D. Shelley's Zastrozzi and St. Irvyne. The Modern Language Review, v. 7, n. 1, January, p. 54-63, 1912.

MCGANN, Jerome J. 'My Brain is Feminine': Byron and the Poetry of Deception. In: RUTHERFORD, Andrew (Org.). Byron: Augustan and Romantic. Basingstoke: Macmillan, p. 26-51, 1990.

MEDWIN, Thomas (1847). The life of Percy Bysshe Shelley. Londres: Oxford University Press, 1913.

MICHASIW, Kim Ian. Introduction. In: DACRE, Charlotte. Zofloya, or the Moor. Nova York: Oxford University Press, p. vii-xxx, 2008.

MILES, Robert. The 1790s: the effulgence of Gothic. In: HOGLE, Jerrold E. The Cambridge Companion to Gothic Fiction. Cambridge: Cambridge University Press, p. 41-62, 2002.

NOVELS AND ROMANCES. Monthly Magazine, Londres, v. 30, July, p. 657, 1807. Available at: https://babel.hathitrust.org/cgi/ pt?id=njp.32101064253212\&view=1up\&seq=655\&q1=libertines. Accessed on: $28^{\text {th }}$ Feb. 2021.

PYKETT, Lyn. Sensation and the Fantastic in the Victorian Novel. In: DAVID, Deirdre (Org.). The Cambridge Companion to the Victorian Novel. Cambridge: Cambridge University Press, p. 192-211, 2001.

REVIEWS. Monthly Literary Recreations, Londres, v. 1, July/ December, p. 80, 1806. Available at: https://babel.hathitrust.org/cgi/ pt id $=$ chi. $79289135 \&$ view $=2$ up\&seq $=6 \&$ size $=125$. Accessed on: $24^{\text {th }}$ Dec. 2019.

THE TERRORIST NOVEL WRITING (1798). The Terrorist Novel Writing. In: CLERY, E.J.; MILES, Robert (Orgs.). Gothic Documents. Manchester: Manchester University Press, p. 182-182, 2000.

THE TIMES. Londres. November, 1825. Available at: https:// www.thetimes.co.uk/archive/article/1825-11-09/4/7. html?region=global\#start\%3D1825-11-07\%26end\%3D1825-11- 
09\%26terms\%3Dbyrne\%26back\%3D/tto/archive/find/byrne/w:182511-07\%7E1825-11-09/1\%26next\%3D/tto/archive/frame/goto/byrne/ w:1825-11-07\%7E1825-11-09/2. Accessed on: 28 Feb. 2021.

THOMSON, Douglas H. Charlotte Dacre. In: THOMSON, Douglas H. et al. Gothic Writers. Westport: Greenwood Press, p. 99-103, 2002.

VASCONCELOS, Sandra Guardini. Dez lições sobre o romance inglês do século XVIII. São Paulo: Boitempo, 2002.

WOOLF, Virginia. Profissões para mulheres. In: WOOLF, Virginia. Profissões para mulheres e outros artigos. São Paulo: L\&PM, p. 9-20, s.d. Disponível em: https://www.lpm-editores.com.br/livros/imagens/ profissoes para mulheres trecho.pdf. Acesso em: 28 fev. 2021. WOOLF, Virginia (1929). Um teto todo seu. Tradução de Vera Ribeiro, 2. ed. Rio de Janeiro: Nova Fronteira, 2019.

\section{Paula Pope Ramos}

Mestra em Literaturas de Língua Inglesa (UERJ), é atualmente estudante de doutorado na área de literatura inglesa na Universidade do Estado do Rio de Janeiro (UERJ/CAPES), com enfoque na poética gótica e as políticas que regem o corpo feminino, bem como os limites da representação da mulher nessas ficções.

E-mail:ppoperamos@gmail.com

Lattes: https://lattes.cnpq.br/2403110523656190

ORCID iD: http://orcid.org/0000-0001-9148-9240 